Editorial

\title{
Novel Research for Development of Shape Memory Alloys
}

\author{
Takuo Sakon
}

Department of Mechanical and Systems Engineering, Faculty of Science and Technology, Ryukoku University, Otsu, Shiga 520-2194, Japan; sakon@rins.ryukoku.ac.jp

Received: 7 February 2018; Accepted: 9 February 2018; Published: 11 February 2018

\section{Introduction and Scope}

Shape memory alloys have attracted much attention due to their attractive properties for applications as well as their basic aspects of deformation and transformation in structural and magnetic behavior. In 1951, the Au-Cd alloy was discovered [1]. After that, numberless shape memory alloys have been developed. A lot of applications of shape memory alloys were realized after the Ti-Ni alloy was found in 1963 and developed extensively in 1980s [2]. Recently, ferromagnetic shape memory alloys (FSMA) have been studied as candidates for highly functional materials [3]. Among FSMA, $\mathrm{Ni}_{2} \mathrm{MnGa}$ is the most renowned [4]. The magnetostriction, or magnetic field induced strain (MFIS) is most featured phenomena. Few $\%$ MFIS were found for some $\mathrm{Ni}_{2} \mathrm{MnGa}$ type single crystals. MFISs of $6.0 \%$ have been produced at room temperature in single crystals of $N_{49.8} \mathrm{Mn}_{28.5} \mathrm{Ga}_{21.7}\left(T_{\mathrm{M}}=318 \mathrm{~K}\right)$ by application of fields of order $400 \mathrm{kA} / \mathrm{m}(=0.50 \mathrm{~T})$ under an opposing stress of order $1 \mathrm{MPa}$ [5]. Fe-Pd and Fe-Pt alloys are also famous FSMA for MFIS. The strain is the result of field-induced twin boundary motion under an atmospheric pressure. A disordered Fe-31.2\%Pd (at \%) alloy (A1-type cubic) [6,7], and an ordered $\mathrm{Fe}_{3} \mathrm{Pt}$ (L12-type cubic) ferromagnetic alloy [8,9], have attracted much interest due to the large MFISs. The alloys which was doped other elements are also studied. The magnetostriction studies on the premartensite phase of related Cr-substituted $\mathrm{Ni}_{2} \mathrm{Mn}_{1-x} \mathrm{Cr}_{x} \mathrm{Ga}$ alloys were studied and robust 120 ppm magnetostriction was observed [10]. New alloys in the Ni-Mn-In, Ni-Mn-Sn, and $\mathrm{Ni}-\mathrm{Mn}-\mathrm{Sb}$ Heusler alloy systems that are expected to be ferromagnetic shape memory alloys have been studied [11]. A re-entrant magnetism was observed in some alloys [12,13]. These alloys are promising as a metamagnetic shape memory alloys with a magnetic field-induced shape memory effect and as magnetocaloric effect [14]. Consequently, these materials are finding use or are candidates as materials for sensors, actuators, magnetic refrigerator, etc. [15].

The dynamical functionality of the nickel-titanium (NiTi)-based alloy comes into the limelight. $\mathrm{NiTi}$ is an attractive alloy due to its unique functional properties, for example, shape memory effect (SMA), elastic deformation, super-elasticity, low stiffness, and damping characteristics $[16,17]$. In this special issue, physical properties are also shown for industrial objects, as joining between the different kind of metals, SMA bolts, and tubes. In our department in Ryukoku Univertsity, we are focused on robotics and applications (mechanical actuators). Therefore, our colleagues shed light on dynamic applications for SMAs.

\section{Contributions}

$\mathrm{Xu}$ et al. prepared $\mathrm{Cu}_{71.5} \mathrm{Al}_{17.5} \mathrm{Mn}_{11}$ shape memory alloy by directional solidification by means of unique homemade equipment [18]. A large maximum recoverable strain of more than $11 \%$ was maintained due to the retained beneficial grain characteristics. Good superelastic behavior was observed.

Hu et al. investigated microstructural evolution of NiTi shape memory alloy (SMA) on the basis of heat treatment and severe plastic deformation (SPD) [19]. Consequently, SPD and subsequent aging 
contribute to enhancing the transformation temperature of martensite. The relation between softening of elastic constants and martensitic transformation has attracted considerable attention for many years and has been discussed [20].

Fukuda et al. investigated the relation between the softening of elastic constants and martensitic transformation in $\mathrm{Fe}_{3} \mathrm{Pt}$ [21]. The softening in shear elastic coefficient $C^{\prime}=\left(C_{11}-C_{12}\right) / 2$ is probably most strongly related to the formation of the face-centered-tetragonal with $\mathrm{c} / \mathrm{a}<1$ (FCT1) martensite. This result implies that softening is most strongly related to the formation of the martensite.

Zhang et al. studied about physical mechanism for dynamic recrystallization of NiTi shape memory alloy subjected to local canning compression at various temperatures, 600, 700, and $800{ }^{\circ} \mathrm{C}$ [22]. In the case of 600 and $700{ }^{\circ} \mathrm{C}$, continuous dynamic recrystallization and discontinuous dynamic recrystallization coexist in NiTi shape memory alloy. In the case of discontinuous dynamic recrystallization, the recrystallized grains are found to be nucleated at grain boundaries and even in grain interiors.

Jiang et al. studied about NiTi shape memory alloy (SMA) tube, which was coupled with mild steel cylinder in order to investigate deformation mechanisms of NiTi SMA tubes undergoing radial loading [23]. Microstructure was characterized by transmission electron microscope. When NiTi SMA tube is subjected to radial loading, strain induced martensite transformation is of great significance in the superelasticity of NiTi SMA, and reorientation and detwinning of twinned martensite lays a profound foundation for the shape memory effect of NiTi SMA.

Shiue et al. studied the infrared dissimilar joining $\mathrm{Ti}_{50} \mathrm{Ni}_{50}$ and $316 \mathrm{~L}$ stainless steel using $\mathrm{Cu}$ foil in between Cusil-ABA and BAg-8 filler metals [24]. This study indicates great potential for industrial applications.

Jiang et al. studied the deformation behavior and microstructure evolution of NiTiCu SMA, which possesses martensite phase at room temperature based on a uniaxial compression test at the temperatures of 700 1000 ${ }^{\circ} \mathrm{C}$ [25]. Dislocations become the dominant substructures of martensite phase in NiTiCu SMA compressed at $700^{\circ} \mathrm{C}$. Martensite twins are dominant in NiTiCu SMA compressed at 800 and $900{ }^{\circ} \mathrm{C}$. The microstructures resulting from dynamic recovery or dynamic recrystallization significantly influence the substructures in the martensite phase of NiTiCu SMA at room temperature.

Liang et al. studied NiTiFeNb and NiTiFeTa SMAs [26]. The microstructure, mechanical property, and phase transformation of $\mathrm{NiTiFeNb}$ and NiTiFeTa SMAs were investigated. As compared to NiTiFe SMA, quaternary NiTiFeNb and NiTiFeTa SMAs possess the higher strength, since solution strengthening plays a considerable role.

The processing map of $\mathrm{Ni}_{47} \mathrm{Ti}_{44} \mathrm{Nb}_{9}$ (at \%) shape memory alloy (SMA), which possesses B2 austenite phases and $\mathrm{Nb}$ phases at room temperature, is established by Wang et al. in order to optimize the hot working parameters [27].

$\mathrm{Hu}$ et al. investigated the texture evolution of NiTi shape memory alloy during uniaxial compression deformation at $673 \mathrm{~K}$ by combining crystal plasticity finite element method with electron back-scattered diffraction experiment and transmission electron microscope experiment [28]. Using the fitted material parameters, a crystal plasticity finite element method is used to predict texture evolution of NiTi shape memory alloy during uniaxial compression deformation. The simulation results agree well with the experimental ones. With the progression of plastic deformation, a crystallographic plane of NiTi shape memory alloy gradually rotates to be vertical to the loading direction, which lays the foundation for forming the $<111>$ fiber texture.

Mitsui et al. observed field-induced reverse transformation in Co-doped Ni-Mn-In film by means of high field $\mathrm{X}$-ray diffraction experiments under magnetic fields up to $5 \mathrm{~T}$ and temperature ranging from 293 to 473 K [29]. The reverse martensitic transformation induced by magnetic fields was directly observed in situ HF-XRD techniques.

Superelastic SMA bolts, which have a recentering capability upon unloading, are fabricated by Seo et al. as to solve drawbacks, and utilized by replacing conventional steel bolts in the partially restrained bolted T-stub connection [30]. 
$\mathrm{Wu}$ et al. investigated damping characteristics of inherent and intrinsic internal friction of $\mathrm{Cu}-\mathrm{Zn}-\mathrm{Al}$ Shape Memory Alloys [31]. The $\mathrm{Cu}-x \mathrm{Zn}-11 \mathrm{Al}$ SMAs are promising for practical high-damping applications under isothermal conditions because they possess good workability, low cost, acceptable mechanical properties, and the high damping capacities.

Adachi et al. made the phase diagram of $\mathrm{Ni}_{2} \mathrm{MnGa}_{1-x} \mathrm{Fe}_{x}$ on the basis of the experimental results [32]. The magnetostructural transitions were observed at the Fe concentrations $x=0.275$, 0.30 , and 0.35. The obtained phase diagram was very similar to that for $\mathrm{Ni}_{2} \mathrm{Mn}_{1-x} \mathrm{Cu}_{x} \mathrm{Ga}$ by Kataoka et al. [33]. The theoretical analysis of the phase diagram for $\mathrm{Ni}_{2} \mathrm{Mn}_{1-x} \mathrm{Cu}_{x} \mathrm{Ga}$ showed that the biquadratic coupling term of the martensitic distortion and magnetization plays an important role in the interplay between the martensitic phase and ferromagnetic phase. Further theoretical investigation of the phase diagram for $\mathrm{Ni}_{2} \mathrm{MnGa}_{1-x} \mathrm{Fe}_{x}$ is needed.

Umetsu et al. performed the specific heat measurements at low temperatures for $\mathrm{Ni}_{50} \mathrm{Mn}_{50-x} \mathrm{In}_{x}$ alloys to determine their Debye temperatures $\theta_{\mathrm{D}}$ and electronic specific heat coefficients $\gamma$, and investigated the change in the density of states during the martensitic phase transformation [34]. The $\gamma$ was slightly larger in the parent phase, in good agreement with the reported density of states around the Fermi energy obtained by the first-principle calculations. The martensite $(M)$ phase $(x \leq 15), \theta_{\mathrm{D}}$ decreases linearly and $\gamma$ increases with increasing Indium content.

Anelastic properties of Ti-Ni-based alloys are widely explored, both for microstructural characterization of the alloys and for their application as high-damping materials [35]. Sapozhnikov et al. investigated the linear and non-linear internal friction, effective Young's modulus, and amplitudedependent modulus defect of a $\mathrm{Ti}_{50} \mathrm{Ni}_{46.1} \mathrm{Fe}_{3.9}$ alloy after different heat treatments, affecting hydrogen content [36]. They found that the internal friction maximum is associated with a competition of two different temperature-dependent processes affecting the hydrogen concentration in the core regions of twin boundaries.

Carl et al. investigated the SMA with high martensitic transformation temperature [37]. Small changes in at $\% \mathrm{Ni}$ have a dramatic effect on the transformation temperatures of the NiTi-20 at \% Zr system, even more so than in binary NiTi. The transformation temperature can be tuned for a given application through aging treatments. Ni-Ti-based shape memory alloys (SMAs) have now become an important technological material for a wide array of applications not only for specifically medical devices [38] but actuators above room temperature [39].

As introduced here, many fundamental research results are shown in 17 articles. There are many SMA materials in which there is possibility of the application for mechanical and/or magnetic actuators, springs, bolts, magnetic refrigeration, sensors, etc.

I hope the results of the research in this special issue contribute to further development of SMAs.

Conflicts of Interest: The author declares no conflict of interest.

\section{References}

1. Chang, L.C.; Read, T.A. Plastic Deformation and Diffusionless Phase Changes in Metals-the Gold-Cadmium Beta Phase. Trans. AIME 1951, 189, 47-52. [CrossRef]

2. Buehler, W.J.; Gilfrich, J.V.; Wiley, R.C. Effect of Low-Temperature Phase Changes on the Mechanical Properties of Alloys near Composition TiNi. J. Appl. Phys. 1963, 34, 1475-1477. [CrossRef]

3. Chernenko, V.A.; Besseghini, S. Ferromagnetic shape memory alloys: Scientific and applied aspects. Sens. Actuators A Phys. 2008, 142, 542-548. [CrossRef]

4. Ullakko, K.; Huang, J.K.; Kantner, C.; O'Handley, R.C.; Kokorin, V.V. Large magnetic-field-induced strains in $\mathrm{Ni}_{2} \mathrm{MnGa}$ single crystals. Appl. Phys. Lett. 1996, 69, 1966-1968. [CrossRef]

5. Murray, S.J.; Marioni, M.; Allen, S.M.; O’Handley, R.C. $6 \%$ magnetic-field-induced strain by twin-boundary motion in ferromagnetic Ni-Mn-Ga. Appl. Phys. Lett. 2000, 77, 886-888. [CrossRef]

6. Kakeshita, T.; Fukuda, T.; Sakamoto, T.; Takeuchi, T.; Kindo, K.; Endo, S.; Kishino, K. Martensitic transformation in shape memory alloys under magnetic field and hydrostatic pressure. Mater. Trans. 2002, 43, 887-892. [CrossRef] 
7. Sakamoto, T.; Fukuda, T.; Kakeshita, T.; Takeuchi, T.; Kishino, K. Magnetic field-induced strain in iron-based ferromagnetic shape memory alloys. J. Appl. Phys. 2003, 93, 8647-8649. [CrossRef]

8. Kakeshita, T.; Fukuda, T. Conversion of variants by magnetic field in Iron-based ferromagnetic shape memory alloys. Mater. Sci. Forum 2003, 426-432, 2309-2314. [CrossRef]

9. Fukuda, T.; Sakomoto, T.; Inoue, T.; Kakeshita, T.; Kishio, K. Influence of magnetic field direction on recoverable strain due to rearrangement of variants in Fe 3 Pt. Trans. Mater. Res. Soc. Jpn. 2004, 29, 3059-3060.

10. Sakon, T.; Fujimoto, N.; Kanomata, T.; Adachi, Y. Magnetostriction of $\mathrm{Ni}_{2} \mathrm{Mn}_{1-x} \mathrm{Cr}_{x} \mathrm{Ga}$ Heusler Alloys. Metals 2017, 7, 410. [CrossRef]

11. Oikawa, K.; Ito, W.; Imano, Y.; Sutou, Y.; Kainuma, R.; Ishida, K.; Okamoto, S.; Kitakami, O.; Kanomata, T. Effect of magnetic field on martensite transformation of $\mathrm{Ni}_{46} \mathrm{Mn}_{41} \mathrm{In}_{13}$ Heusler alloy. Appl. Phys. Lett. 2006, 88, 122507. [CrossRef]

12. Kainuma, R.; Imano, Y.; Ito, W.; Sutou, Y.; Morino, H.; Okamoto, S.; Kitakami, O.; Oikawa, K.; Fujita, A.; Kanomata, T.; et al. Magnetic-field-induced shape recovery by reverse phase transformation. Nature 2006, 439, 957-960. [CrossRef] [PubMed]

13. Sakon, T.; Sasaki, K.; Numakura, D.; Abe, M.; Nojiri, H.; Adachi, Y.; Kanomata, T. Magnetic field-induced transition in Co-Doped $\mathrm{Ni}_{41} \mathrm{Co}_{9} \mathrm{Mn}_{31.5} \mathrm{Ga}_{18.5}$ Heusler Alloy. Mater. Trans. 2013, 54, 9-13. [CrossRef]

14. Sakon, T.; Kitaoka, T.; Tanaka, K.; Nakagawa, K.; Nojiri, H.; Adachi, Y.; Kanomata, T. Vadim Glebovsky. Magnetocaloric and magnetic properties of meta-magnetic Heusler alloy $\mathrm{Ni}_{41} \mathrm{Co}_{9} \mathrm{Mn}_{31.5} \mathrm{Ga}_{18.5}$. In Progress in Metallic Alloys; InTech: Rijeka, Croatia, 2016; pp. 265-287.Ni41Co9Mn31.5Ga18.5. In Progress in Metallic Alloys; InTech: Rijeka, Croatia, 2016; pp. 265-287.

15. Niemann, R.; Hahn, S.; Diestel, A.; Backen, A.; Schultz, L.; Nielsch, K.; Wagner, M.F.-X.; Fähler, S. Reducing the nucleation barrier in magnetocaloric Heusler alloys by nanoindentation. Appl. Phys. Letter. Mater. 2016, 4, 064101. [CrossRef]

16. Otsuka, K.; Ren, X. Physical metallurgy of Ti-Ni-based shape memory alloys. Prog. Mater. Sci. 2005, 50, 511-678. [CrossRef]

17. Elahinia, M.; Moghaddam, N.S.; Andani, M.T.; Amerinatanzi, A.; Bimber, B.A.; Hamilton, R.F. Fabrication of NiTi through additive manufacturing: A review. Prog. Mater. Sci. 2016, 83, 630-663. [CrossRef]

18. Xu, S.; Huang, H.; Xie, J.; Kimura, Y.; Xu, X.; Omori, T.; Kainuma, R. Dynamic Recovery and Superelasticity of Columnar-Grained Cu-Al-Mn Shape Memory Alloy. Metals 2017, 7, 141. [CrossRef]

19. Hu, L.; Jiang, S.; Zhang, Y. Role of Severe Plastic Deformation in Suppressing Formation of R Phase and $\mathrm{Ni}_{4} \mathrm{Ti}_{3}$ Precipitate of NiTi Shape Memory Alloy. Metals 2017, 7, 145. [CrossRef]

20. Dai, L.; Cullen, J.; Wuttig, M. Intermartensitic transformation in a NiMnGa alloy. J. Appl. Phys. 2004, 95, 6957-6959. [CrossRef]

21. Fukuda, T.; Kakeshita, T. Lattice Softening in $\mathrm{Fe}_{3} \mathrm{Pt}$ Exhibiting Three Types of Martensitic Transformations. Metals 2017, 7, 156. [CrossRef]

22. Zhang, Y.; Jiang, S.; Hu, S. Investigation of Dynamic Recrystallization of NiTi Shape Memory Alloy Subjected to Local Canning Compression. Metals 2017, 7, 208. [CrossRef]

23. Jiang, S.; Junbo, Y.; Hu, L.; Zhang, Y. Investigation on Deformation Mechanisms of NiTi Shape Memory Alloy Tube under Radial Loading. Metals 2017, 7, 268. [CrossRef]

24. Shiue, R.K.; Wu, S.K.; Yang, S.H.; Liu, C.K. Infrared Dissimilar Joining of $\mathrm{Ti}_{50} \mathrm{Ni}_{50}$ and 316L Stainless Steel with Copper Barrier Layer in between Two Silver-Based Fillers. Metals 2017, 7, 276. [CrossRef]

25. Jiang, S.; Sun, D.; Zhang, Y.; Hu, L. Deformation Behavior and Microstructure Evolution of NiTiCu Shape Memory Alloy Subjected to Plastic Deformation at High Temperatures. Metals 2017, 7, 294. [CrossRef]

26. Liang, Y.; Jiang, S.; Zhang, Y.; Yu, J. Microstructure, Mechanical Property, and Phase Transformation of Quaternary NiTiFeNb and NiTiFeTa Shape Memory Alloys. Metals 2017, 7, 309. [CrossRef]

27. Wang, Y.; Jiang, S.; Zhang, Y. Processing Map of NiTiNb Shape Memory Alloy Subjected to Plastic Deformation at High Temperatures. Metals 2017, 7, 328. [CrossRef]

28. Hu, L.; Jiang, S.; Zhang, Y. A Combined Experimental-Numerical Approach for Investigating Texture Evolution of NiTi Shape Memory Alloy under Uniaxial Compression. Metals 2017, 7, 356.

29. Mitsui, Y.; Koyama, K.; Ohtsuka, M.; Umetsu, R.Y.; Kainuma, R.; Watanabe, K. High Field X-ray Diffraction Study for $\mathrm{Ni}_{46.4} \mathrm{Mn}_{38.8} \mathrm{In}_{12.8} \mathrm{Co}_{2.0}$ Metamagnetic Shape Memory Film. Metals 2017, 7, 364. [CrossRef]

30. Seo, J.; Hu, J.W.; Kim, K.H. Analytical Investigation of the Cyclic Behavior of Smart Recentering T-Stub Components with Superelastic SMA Bolts. Metals 2017, 7, 386. [CrossRef] 
31. Wu, S.K.; Chan, W.J.; Chang, S.H. Damping Characteristics of Inherent and Intrinsic Internal Friction of Cu-Zn-Al Shape Memory Alloys. Metals 2017, 7, 397. [CrossRef]

32. Adachi, Y.; Ogi, Y.; Kobayashi, N.; Hayasaka, Y.; Kanomata, T.; Umetsu, R.Y.; Xu, X.; Kainuma, R. Temperature Dependences of the Electrical Resistivity on the Heusler Alloy System $\mathrm{Ni}_{2} \mathrm{MnGa}_{1-x} \mathrm{Fe}_{x}$. Metals 2017, 7, 413. [CrossRef]

33. Kataoka, M.; Endo, K.; Kudo, N.; Kanomata, T.; Nishihara, H.; Shishido, T.; Umetsu, R.Y.; Nagasako, M.; Kainuma, R. Martensitic transition, ferromagnetic transition, and their interplay in the shape memory alloys $\mathrm{Ni}_{2} \mathrm{Mn}_{1-x} \mathrm{Cu}_{x} \mathrm{Ga}$. Phys. Rev. B 2010, 82, 214423. [CrossRef]

34. Umetsu, R.Y.; Xu, X.; Ito, W.; Kainuma, R. Evidence of Change in the Density of States during the Martensitic Phase Transformation of Ni-Mn-In Metamagnetic Shape Memory Alloys. Metals 2017, 7, 414. [CrossRef]

35. Blanter, M.S.; Golovin, I.S.; Neuhäuser, H.; Sinning, H.-R. Internal Friction in Metallic Materials; A Handbook; Springer: Berlin/Heidelberg, Germany, 2007.

36. Sapozhnikov, K.; Torrens-Serra, J.; Cesari, E.; Humbeeck, J.V.; Kustov, S. Effect of Hydrogen on the Elastic and Anelastic Properties of the $\mathrm{R}$ Phase in $\mathrm{Ti}_{50} \mathrm{Ni}_{46.1} \mathrm{Fe}_{3.9}$ Alloy. Metals 2017, 7, 493. [CrossRef]

37. Carl, M.; Smith, J.D.; Doren, B.V.; Young, M.L. Effect of Ni-Content on the Transformation Temperatures in NiTi-20 at \% Zr High Temperature Shape Memory Alloys. Metals 2017, 7, 511. [CrossRef]

38. Pelton, A.; Duerig, T.; Stöckel, D. A guide to shape memory and superelasticity in nitinol medical devices. Minim. Invasive Ther. Allied Technol. 2004, 13, 218-221. [CrossRef] [PubMed]

39. Benafan, O.; Brown, J.; Calkins, F.; Kumar, P.; Stebner, A.; Turner, T.; Vaidyanathan, R.; Webster, J.; Young, M. Shape memory alloy actuator design: Casmart collaborative best practices and case studies. Int. J. Mech. Mater. Des. 2014, 10, 1-42. [CrossRef]

(C) 2018 by the author. Licensee MDPI, Basel, Switzerland. This article is an open access article distributed under the terms and conditions of the Creative Commons Attribution (CC BY) license (http:/ / creativecommons.org/licenses/by/4.0/). 